\title{
Errata For Earthquake Bulletin Vol. 30, No 4, December 1997
}

\section{Replacement diagrams for page 278}

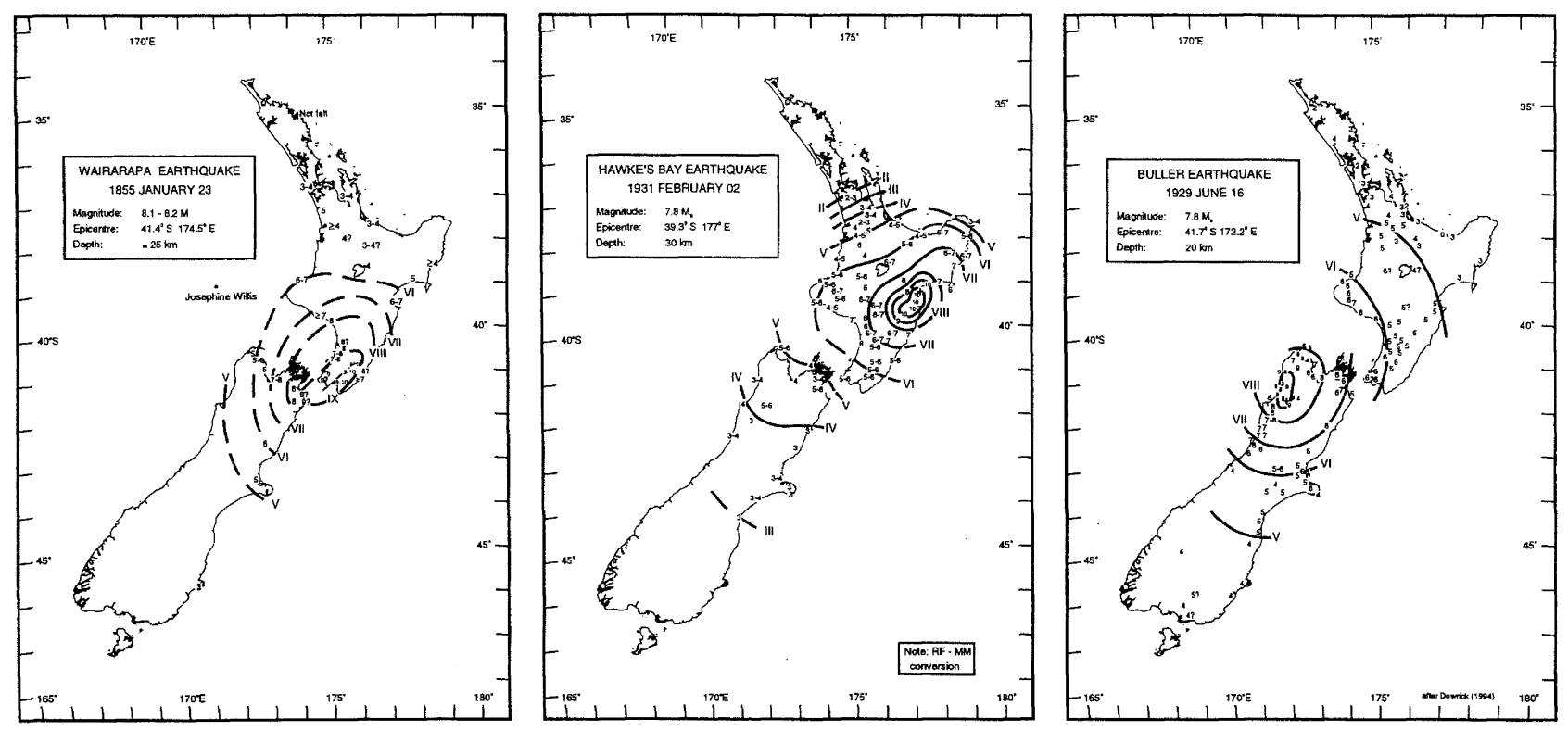

Fig. 2. Comparison of isoseismals for the 1855 (Wairarapa), 1931 (Hawke's Bay), and 1929 (Buller) earthquakes. Isoseismal maps of the Hawke's Bay and Buller earthquakes are from Downes (1955).

\section{Page 336, Second Column, under the heading "TSUNAMI AND SEISMIC} SEICHE" the first paragraph should read:

Abnormal tidal movements in the Cook Strait area and the continuous ebbing and flowing of tides in Wellington Harbour for 8-12 hours following the main shock on January 231855 were widely reported in contemporary newspapers. Consequently the occurrence of the tsunami in Cook Strait, with waves up to 9 10 metres high in Palliser Bay, and the seiching of Wellington Harbour in response to the tsunami and the effect of differential uplift has been well known for a number of years. De Lange et al. (1986) include the event in their listing of tsunami known to have been experienced in New Zealand and the effects in Wellington Harbour have been modelled by Barnett et al (1991). The data on the tsunami and seiching effects throughout New Zealand presented here are more extensive than were available to De Lange et al. or Barnett et al. 